\title{
De äldre runorna på Rökstenen
}

\author{
Staffan Fridell (Uppsala University) och \\ Henrik Williams (Uppsala University)
}

\begin{abstract}
A short section of the runic inscription on the Rök stone (Ög 136) is written mainly in runes from the older, 24-type futhark. This use has for a long time been considered a form of cryptography, one of several in the inscription. The older runes are used to represent their corresponding runes from the younger, 16-type futhark, but in a reversed, "mirrored" manner; for example, whereas the younger futhark's $\mathbf{t}$ rune is used for $[t]$ and $[d]$, the $\mathbf{D}$ rune has that same function in this part of the Rök inscription. There are in addition two unique runes in the section, corresponding to $\mathbf{a}$ and $\mathbf{i}$ respectively, which are probably variants of the old jära- and ihwar-runes, both of which adhere to the acrophonic principle of orthography.
\end{abstract}

Keywords: Ög 136 Rök runic inscription, older futhark runes, cryptography, runic orthography, acrophonic principle

$\mathrm{C}_{\mathrm{tt}}$ kortare avsnitt av runtexten på Ȯg 136 Rökstenen är skrivet till Estörsta delen med runor från den äldre, 24-typiga futharken. Det råder stor enighet om läsningen av själva runorna (här återgiven efter Holmberg, Gräslund, Sundqvist och Williams 2020, 24):

\section{SAGWMOGMENÏ|PADHOARÏGOLD}

GAOaRÏGolDïnDGOgnARHOSlï

Konsensus råder även om att detta av ristaren är avsett att motsvara denna text med yngre 16-typiga runor:

sakumukminipathuarikult

kauarikultintkugnarhusli

Här kommer inte tolkningen av texten att fokuseras utan i stället användningen av äldre runor. Varför använde ristaren dem och vilka principer avgjorde valet av runor?

Fridell, Staffan, and Henrik Williams. "De äldre runorna på Rökstenen."

Futhark: International fournal of Runic Studies 11 (2020, publ. 2021): 167-71.

DOI: $10.33063 /$ diva- 438141 
Av de 15 runor som förekommer hör 6 uteslutande hemma i den äldre futharken (eller i övergångsinskrifter): XPHMX人. En runa har analyserats som en hybridform mellan $\lceil$ och $\$ som uppkommit genom att ristaren av misstag först ristat ett kortkvist-m och sedan försökt rätta sig genom att göra runan mer lik $\mathbf{m}$ från äldre runraden. Två runor, $\mathbf{k}$ och $\mathbb{Q}$, som står för a respektive $\mathbf{i}$, har unika former och deras ursprung är omdiskuterat. Slutligen används en typ av lönnruna för $\mathbf{p}$.

Det är Aslak Liestøls (1981) analys av användningen av äldre runor på Rökstenen som kan sägas vara den numera dominerande. Michael Barnes (2007, 124) ser hans teori som "tiltalende" och Jonas Nordby $(2018,119)$ skriver att förklaringen är "besnærende, og gir en logisk årsak till mange av tegnene”. Vi menar emellertid att Liestøls analys är onödigt komplicerad och att det finns en enklare förklaring - som enligt Ockhams rakkniv är att föredra - vilken också tydligare visar hur ristaren medvetet använder de äldre runorna som ett kryptografiskt system, som lönnrunor.

Grundläggande för Liestøls teori är antagandet att Rökinskriftens unika form av a-runa $\$$ uppfattas som utvecklad ur den äldre $\mathbf{p}$-runan $\boldsymbol{\complement}$, medan den lika unika i-runans form $\&$ härleds från den äldre j-runan med namnet *jāra $>\bar{a} r \varsigma$. För att få detta att stämma med runornas respektive namn och därmed ljudvärde, tvingas Liestøl räkna med att det vid någon tidpunkt i runradens tradering skett en förväxling av namnen på runor som stått intill varandra i den äldre futharken. Resultatet har blivit att den äldre j-runan övertagit namnet iss och ljudvärdet [i] från runan I, medan den äldre p-runan övertagit namnet *jāra > ār och ljudvärdet [a] från runan 9 . Detta är en visserligen skarpsinnig men trots allt mycket långsökt förklaring. Framför allt är det svårt att förstå hur man kan ha förväxlat namnet och ljudvärdet på den till formen allra enklaste runan I, som måste ha varit den som var allra lättast att lära sig och komma ihåg och som ju även fortlever med samma form, namn och ljudvärde i den yngre futharken.

Allting blir mycket enklare och logiskt om man i stället, liksom tidigare forskare, antar att Rökstenens a-runa $\$$ är en av flera sent utvecklade varianter av *jāra-runan (Bugge 1910, 178, von Friesen 1920, 26) och att den speciella i-runan $\&$ till sin form kan härledas från den äldre ${ }^{*} i h w a^{-}$ runan 1 (Frits Läffler i referat hos Bugge 1910, 178, och von Friesen 1920, 26). ${ }^{1}$ Då stämmer runornas härledning med ljudvärdet enligt den akrofona principen utan att man behöver förutsätta rockader och förväxlingar. Runan 1 verkar visserligen tidigt ha upphört att användas i löpande text

${ }^{1}$ Benämningen av (eller namnet på) runorna $\mathcal{L}$ och $M$ är omdiskuterade men liksom Liestøl $(1981,251)$ utgår vi från att de var * $i(h)$ war respektive * ehwar.

Futhark $11(2020)$ 
i runinskrifter, men kan ha levt kvar i traderingen av den äldre futharken (Liestøl 1981, 259) och förekommer för övrigt sannolikt på Rökstenen i ett avsnitt med positionsrunor som utläses pur.

Rökristaren har säkert haft kännedom om namnen på de äldre runorna och via den akrofona principen därmed även om deras ljudvärde. Traderingen av dessa runnamn måste ha varit muntlig, inte som von Friesen $(1920,24)$ hävdar genom att runnamnen nedristats med runor. Runnamnen har förstås vid 800-talets början existerat i en samtida språkform.

Det råder stor enighet om att man bör se användningen av äldre runor på Rökstenen som en lönnskrift, genom att det är frågan om ett äldre skriftsystem som inte längre användes i dagligt bruk och som bara en liten krets människor haft kunskap om, och också genom att man använder de äldre runorna enligt vikingatida runortografiska principer: "innenfor rammen av den yngre fuparken" (Barnes 2007, 124). Men dessutom tillämpar ristaren dessa principer "omvänt" i förhållande till den yngre futharken. Detta blir ett sätt att ytterligare försvåra för läsaren.

Runan D har haft namnet *dagR och stått för uttalet [d]. I den yngre futharken används $t$-runan för [d], förutom för [t]. Men rökristaren låter omvänt $\mathbf{D}$-runan stå för $[t]$, förutom för [d], med bibehållande av principen att en och samma konsonantruna används både för tonande och tonlös konsonant.

Motsvarande gäller för G-runan med det samtida namnet *gjqbu. Rökristaren använder den för $[\mathrm{k}]$, förutom för $[\mathrm{g}]$, medan vikingatida ristare gör det motsatta, använder $\mathbf{k}$ för $[\mathrm{g}]$, förutom för [k].

Ordet odal är i de nordiska fornspråken konsekvent belagt: fornvästnordiska óðal, fornsvenska opal. Runan $\mathbf{X}$ bör därmed haft det nordiska

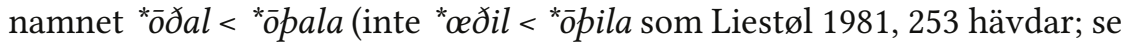
Bjorvand och Lindeman 2019, 900) och alltså ljudvärdet [o(:)]. Vikingatida ristare använder u-runan förutom för [u(:)] också för [o(:)] liksom även för $[\mathrm{y}(:)]$ och $[\mathrm{w}]$, men rökristaren omvänt o för [u(:)] liksom även för $[\mathrm{w}]$ och - kanske - [y] i Ygg och gyldinga (Holmberg, Gräslund, Sundqvist och Williams 2020, 24). Den vikingatida runan u byter så att säga plats och roll med den äldre runan $\mathbf{0}$, men inom samma ortografiska system.

Runan P borde (enligt schemat hos Myrvoll 2012,29) vid 800-talets början haft namnet * $y$ ni och alltså ljudvärdet [y] och kan därför i Rökinskriften translittereras $\mathbf{Y}$ för att ansluta till det antagna ljudvärde som representeras. I vikingatida normalortografi (före de stungna runorna) används $\mathbf{u}$ för $[\mathrm{y}(:)]$, på Rökstenen i detta fall i stället $\mathbf{Y}$ för [u].

Runan M bör enligt vad som vanligen antas ha hetat ${ }^{*} j \overline{0} R<{ }^{*} e h w a R$ och alltså haft ljudvärdet [j] och kan därför i Rökinskriften translittereras j av 
Tabell 1. En "omvänd" tillämpning av den yngre futharkens ortografi på Rökstenen

\begin{tabular}{|c|c|c|c|}
\hline \multicolumn{2}{|c|}{ Yngre futharken } & \multicolumn{2}{|c|}{ Rök } \\
\hline$\uparrow$ & $\mathbf{t}[\mathrm{t}, \mathrm{d}]$ & A & $\mathbf{D}[\mathrm{d}, \mathrm{t}]$ \\
\hline$r$ & $\mathbf{k}[\mathrm{k}, \mathrm{g}]$ & $x$ & $\mathbf{G}[\mathrm{g}, \mathrm{k}]$ \\
\hline n & $\mathbf{u}[\mathrm{y}]$ & $p$ & $\mathbf{Y}[\mathrm{u}]$ \\
\hline n & $\mathbf{u}[\mathrm{o}(:), \mathrm{y}, \mathrm{w}]$ & $\hat{x}$ & $\mathbf{o}[\mathrm{u}(:), \mathrm{y}, \mathrm{w}]$ \\
\hline I & $\mathbf{i}[j]$ & $M$ & $\mathbf{j}[\mathrm{i}]$ \\
\hline
\end{tabular}

samma skäl som för Y. I vikingatida normalortografi används i för [j], på Rökstenen i detta fall i stället $\mathbf{j}$ för - sannolikt - [i] i minni (Holmberg, Gräslund, Sundqvist och Williams 2020, 18, 24). Hypotesen om "omvänd" tillämpning av den vikingatida runortografin är i detta fall faktiskt ett argument för att runföljden ska läsas minni (och inte mænni).

Denna "omvända" tillämpning av den yngre futharkens ortografi på Rökstenen kan schematiskt sammanfattas som i tabell 1.

Runan som i övriga fall står för [i(:)] \& utgår sannolikt från 1. Det är visserligen en för Rökstenen unik form men den har knappast skapats av Rökristaren utan är möjligen en redan tidigare förekommande variant i den äldre runraden. För detta talar att man kan se den som en facilitering genom att de två bistavarna vid ristning $\mathrm{i}$ trä binds samman och kan ristas $i$ ett drag (jfr dalrune- $\nmid$ av äldre $\nVdash$, samt $\zeta$ och det $R$ där bistaven ristas i ett drag). Den aktuella runan bör ha haft det östnordiska namnet ${ }^{*}{ }_{i R}<{ }^{*} i h w a R$ och alltså ljudvärdet [i(:)]. Jfr den vikingatida runan $\downarrow$ i användning i Östnorden som vokalruna med samma ljudvärden som I (se Larsson 2002, 155). Ristaren har alltså om detta är korrekt haft tillgång till två olika runor med ljudvärdet [i(:)]: I ${ }^{*} \bar{\imath} s$ och en variant av $\mathcal{l}{ }^{*}{ }_{i R}$ och väljer då den senare för att öka svårigheten att läsa texten.

Att ristaren brukar två olika runor för [u(:)] respektive [i(:)] beror knappast på en avancerad ljudanalys av någon fonetisk skillnad, utan sannolikt bara, som Nordby $(2018,118)$ alternativt föreslår, för att genom variationen ytterligare utmana läsaren.

\section{Bibliografi}

Barnes, Michael P. 2007. "Rök-steinen: Noen runologiske og språklige overveielser." Maal og minne 99: 120-32. 
Bjorvand, Harald, och Fredrik Otto Lindeman. 2019. Våre arveord: Etymologisk ordbok. 3 utg. Oslo.

Bugge, Sophus. 1910. Der Runenstein von Rök in Östergötland, Schweden. Red. Magnus Olsen. Stockholm.

von Friesen, Otto. 1920. Rökstenen: Runstenen vid Röks kyrka, Lysings härad, Östergötland. Stockholm.

Holmberg, Per, Bo Gräslund, Olof Sundqvist och Henrik Williams. 2020. "The Rök Runestone and the End of the World." Futhark 9-10 (2018-2019): 7-38.

Larsson, Patrik. 2002. Yrrunan: Användning och ljudvärde i nordiska inskrifter. Runrön, 17. Uppsala.

Liestøl, Aslak. 1981. "The Viking Runes: The Transition from the Older to the Younger FUPARK." Saga-Book 20: 247-66.

Myrvoll, Klaus Johan. 2012. "Framvoksteren av sterkt hokyn frå urnordisk till norrønt.” I Germansk filologi og norske ord: Festskrift till Harald Bjorvand på 70-årsdagen den 30. juli 2012, red. John Ole Askedal, Tom Schmidt och Rolf Theil, 16-32. Oslo.

Nordby, K. Jonas. 2018. "Lønnruner: Kryptografi i runeinnskrifter fra vikingtid og middelalder." Ph.d.-avhandling (opublicerad), Institutt for lingvistiske og nordiske studier, Universitetet i Oslo. http://urn.nb.no/URN:NBN:no-69539

Òg 136 = inskrift på Rökstenen publicerad i Östergötlands runinskrifter, av Erik Brate, vol. 2 av Sveriges runinskrifter, publicerade av Kungl. Vitterhets Historie och Antikvitets Akademien (Stockholm, 1911-18). 
